\title{
The provocative lumbar facet joint
}

\author{
David S. Binder · Devi E. Nampiaparampil
}

Published online: 31 March 2009

(C) The Author(s) 2009. This article is published with open access at Springerlink.com

\begin{abstract}
Low back pain is the most common pain symptom experienced by American adults and is the second most common reason for primary care physician visits. There are many structures in the lumbar spine that can serve as pain generators and often the etiology of low back pain is multifactorial. However, the facet joint has been increasingly recognized as an important cause of low back pain. Facet joint pain can be diagnosed with local anesthetic blocks of the medial branches or of the facet joints themselves. Subsequent radiofrequency lesioning of the medial branches can provide more long-term pain relief. Despite some of the pitfalls associated with facet joint blocks, they have been shown to be valid, safe, and reliable as a diagnostic tool. Medial branch denervation has shown some promise for the sustained control of lumbar facet jointmediated pain, but at this time, there is insufficient evidence that it is a wholly efficacious treatment option. Developing a universal algorithm for evaluating facet joint-mediated pain and standard procedural techniques may facilitate the performance of larger outcome studies. This review article provides an overview of the anatomy, pathophysiology, diagnosis, and treatment of facet joint-mediated pain.
\end{abstract}

Keywords Facet joint - Zygapophyseal joint . Low back pain · Pain · Radiculopathy $\cdot$ Sciatica .

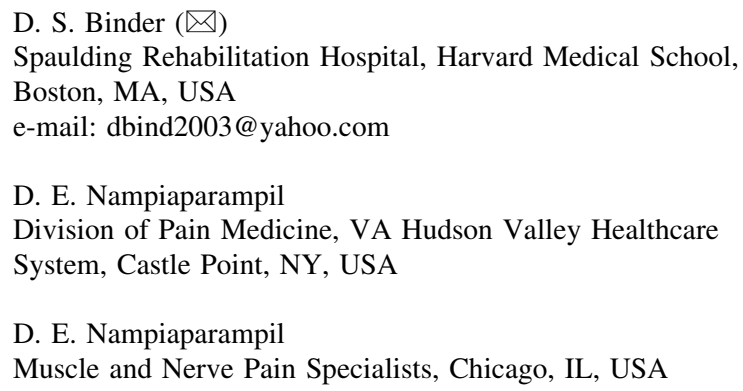

Catheter ablation $\cdot$ Steroids $\cdot$ Lumbar vertebrae . Humans $\cdot$ Male $\cdot$ Female $\cdot$ Nerve block $\cdot$ Diagnostic errors

\section{Introduction}

Low back pain is the most common pain symptom experienced by American adults and is the second most common reason for primary care physician visits [1]. One study reported that over one-quarter of the U.S. population had experienced an episode of low back pain in the three months prior to the survey [2]. Although the majority of episodes last less then 3 months, many patients experience recurrent attacks [3]. Those patients who go on to develop chronic low back pain (lasting greater than 3 months) account for an estimated $\$ 100-\$ 200$ billion dollars of healthcare spending per year [4]. Despite our enhanced understanding of pain neural pathways and improvements in imaging technology, diagnosing the exact etiology of low back pain and treating it continues to be a challenge.

There are many structures in the lumbar spine that can serve as pain generators and often, the etiology of low back pain is multifactorial. Since being described as a potential pain generator by Joel Goldthwait in 1911 [5], the facet joint has been increasingly recognized as an important cause of low back pain. The use of the term facet syndrome was first coined by Ghormely in 1933 [6]. A facet joint (also referred to as a zygapophysial joint) is located at the junction of the inferior articular process of a more cephalad vertebra and the superior articular process of a more caudal vertebra. It has been estimated that facet joint pathology is a contributory factor in $15-52 \%$ of patients with chronic low back pain [7-13]. However, it has also been reported that the prevalence of isolated facet joint pain may be as low as $4 \%$ [14]. 
Although the prevalence of isolated facet joint pain is debatable, the presence of facet joint arthrosis in different age groups is clear. Eubanks et al. examined prevalence rates of facet arthrosis on 647 cadaveric lumbar spines. Fifty-seven percent of samples between 20 and 29 years of age and $93 \%$ of the samples between 40 and 49 years of age had evidence of facet arthrosis. By the age of $60,100 \%$ of the samples had prominent facet arthrosis. The highest prevalence and the greatest severity of arthrosis were found at L4-L5 [15].

Facet joint pain can be diagnosed and treated with facet joint injections and eventually, with radiofrequency lesioning of the medial branches. These are some of the most common interventional pain procedures performed with over 175,000 Medicare billings recorded in 2001 [16].

This review article will provide an overview of the anatomy, pathophysiology, diagnosis, and treatment of facet joint-mediated pain.

\section{Anatomy}

Previous studies have demonstrated that both the capsule $[17,18]$, and synovial folds $[19,20]$ of facet joints possess nociceptive nerve endings. Pain sensation from the capsule and synovium are transmitted through the medial branches of the dorsal ramus of spinal nerves. In addition, the medial branches also supply the multifidus muscle, ligaments, and the periosteum of the vertebral arches and spines [21, 22].

The facet joint in the lumbar spine is innervated by the medial branch of the dorsal ramus of the nerve exiting at the same level and also the medial branch of the nerve one level above. For example, when considering the L4-L5 facet joint, innervation is supplied by the medial branches originating from the L3 and L4 nerves. In this example, the medial branch from the L3 nerve supplies the inferior articular process of the L4 vertebrae. This is equivalent to the superior articulation of the facet joint. Likewise, the medial branch of the L4 nerve supplies the superior articular process of the L5 vertebrae, which also represents the inferior articulation of the L4-L5 facet joint.

As each medial branch passes inferiorly, it lies in a groove along the medial-posterior surface of the transverse process [23-26]. The medial branch courses over the transverse processes one level inferior to where it originates. This is related to the fact that there is a $\mathrm{C} 8$ nerve but no $\mathrm{C} 8$ vertebrae. For example, the $\mathrm{C} 6-\mathrm{C} 7$ facet joint is innervated by the medial branches of $\mathrm{C} 6$ and $\mathrm{C} 7$. However, the $\mathrm{C} 7-\mathrm{T} 1$ facet joint is innervated by the medial branches of $\mathrm{C} 7$ and $\mathrm{C} 8$. The facet joints of $\mathrm{T} 1-\mathrm{T} 2$ are innervated by the medial branches of $\mathrm{C} 8$ and $\mathrm{T} 1$. This pattern continues in the lumbar spine. Of note, the anatomy of the L5-S1 facet joint differs from its lumbar counterparts. It is

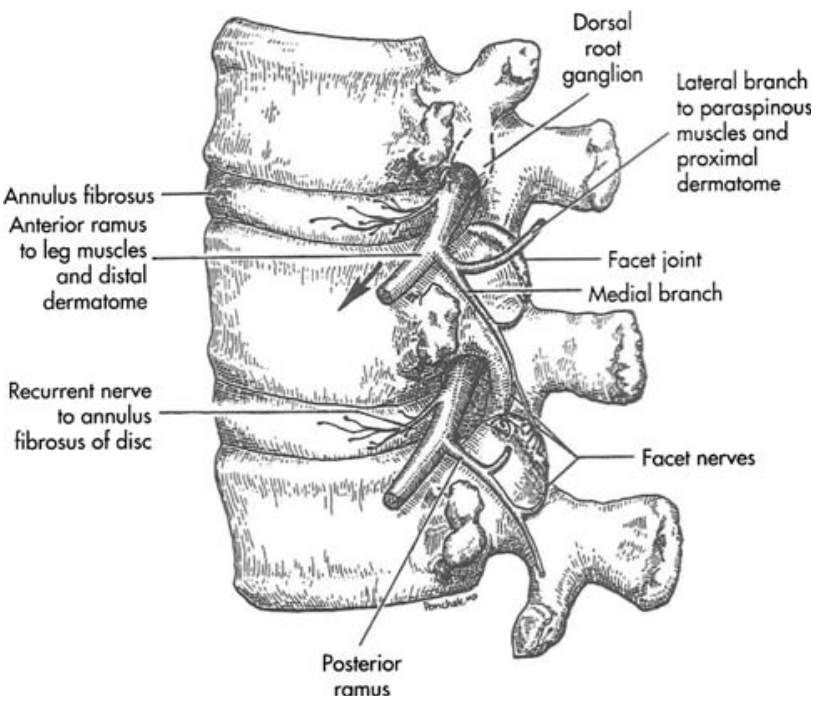

Fig. 1 Anatomic features in the lumbar spine. Adapted from illustration by Stephen Ponchak MD in Walsh NE. Nociceptive Pain. In Raj PP, editor: Pain Medicine a Comprehensive Review, second ed. Elsevier Science, 2003. With permission

innervated by the medial branch of L4 and the dorsal ramus of L5. The L5 dorsal ramus courses along a groove formed between the base of the $\mathrm{S} 1$ superior articulating process and the sacral ala [23, 26] (Fig. 1).

The articulating surface of the facet joints is covered by a layer of hyaline cartilage. Surrounding each facet joint is a thin fibrous capsule lined with synovial membrane. The joint capsule plays an important role in the degree of motion obtainable secondary to the ability of the capsule to resist flexion moments [27]. In comparison to cervical facet joint capsules, the lumbar capsules are shorter and more taught, resulting in a lesser degree of flexion obtained in the lumbar spine in comparison to the cervical spine. Experiments in which the joint capsules in the lumbar spine were excised resulted in increased lumbar range of motion in the sagittal plane [28].

The orientation of lumbar facet joints has important functional and clinical consequences. For example, facet joints oriented relatively more parallel to the sagittal plane, such as at L2-L3 and L3-L4, allow limited rotational movements and anatomically favor flexion and extension movements. In contrast, the L4-L5 facet joints, with increased coronal angulations, facilitate greater rotational movements [29-31].

Both facet joint orientation and facet joint tropism (an asymmetry in the angles of two facet joints at the same level) have been implicated as important variables leading to facet joint-mediated pain. Masharawi et al. examined facet joint morphology in 240 human cadavers. They noted facet joint tropism was much more common in the thoracic spine as compared to the lumbar spine [32]. This suggested that asymmetry of facet joints in the lumbar spine may be 
associated with pathology. However, Grogan et al. [33] examined 104 cadaveric facet joints for severity of cartilage degeneration and found no association with facet tropism. They reported that the factors associated with sclerosis and cartilage degeneration of the facet joint were not facet tropism, but rather advanced age, spinal level, and increasingly coronal joint angles. However, other studies have linked degenerative spondylolisthesis to facet joints that have an increased sagittal orientation [34, 35].

Facet joints may also serve important proprioceptive functions. This is based on the presence of low threshold, mechanoreceptors lining the facet capsule. These receptors are similar to mechanosensitive neurons involved in proprioception of other peripheral joints [36, 37].

Radiographically, the facet joint may be visualized more clearly with oblique views. With this radiographic angle, the classic "Scotty dog" is visualized, allowing for easier recognition of anatomic landmarks. To review, the nose is formed by the transverse process; the eye formed by the pedicle, the neck is the pars interarticularis, the ear is formed by the superior articular process and the front leg formed by the inferior articular process (Fig. 2).

\section{The facet joint as a pain mediator}

In 1963, Hirsch et al. [38] injected 11\% hypertonic saline in the region of the facet joints and provoked low back and thigh pain. Subsequently, facet joint-mediated pain was confirmed with more specific studies involving direct intraarticular injections of hypertonic saline [39, 40]. In the study conducted by Mooney and colleagues, the intraarticular injection of saline was followed by the injection of local anesthetic. This obliterated the discomfort in all subjects tested [39]. Similar results were obtained with subsequent experiments that utilized intra-articular injection of contrast to provoke pain through distention of the facet joint capsule [41]. The results of these earlier studies have been reproduced through experiments involving stimulation of not only facet joints but also the medial branches [42].

The development of facet joint-mediated pain involves both biomechanical and inflammatory components. Multiple factors can destabilize the facet joint and its capsule.

\section{Biomechanical model}

Intervertebral disc degeneration has been reported to be a source of low back pain in adults [43]. Studies have linked pathological changes in facet joints with preceding disc degeneration [44-46]. The intervertebral discs support most of the weight during flexed postures but the facet joints bear an increasingly greater burden as the lumbar spine is ranged into extension. In addition to stabilizing the spine and guiding segmental motion, facet joints function as weight-bearing structures that support axial loading along with the intervertebral discs. Studies have shown that the facet joints can carry up to $33 \%$ of the dynamic axial load [47-49]. Disc degeneration with associated narrowing of the disc space alters the mechanical load distribution and may result in a degenerative cascade with increased mechanical stress on the facet joint and joint capsule. Within the active range of the lumbar spine, the paraspinal muscles act as the principal contributors to vertebral stability. However, both cyclic and sustained flexion movements decrease the reflexive muscle activity of the paraspinal muscles such as the multifidus muscle [50-57]. In theory, this may result in increased laxity across the facet joint leading to both decreased stability and increased stress on the facet joint capsule [55].

The role of the facet joint capsule in stabilizing the motion characteristics of these joints cannot be understated. Studies have suggested that disc degeneration results in
Fig. 2 Oblique view of the lumbar spine. SAP superior articular process, IAP inferior articular process, $P$ pedicle

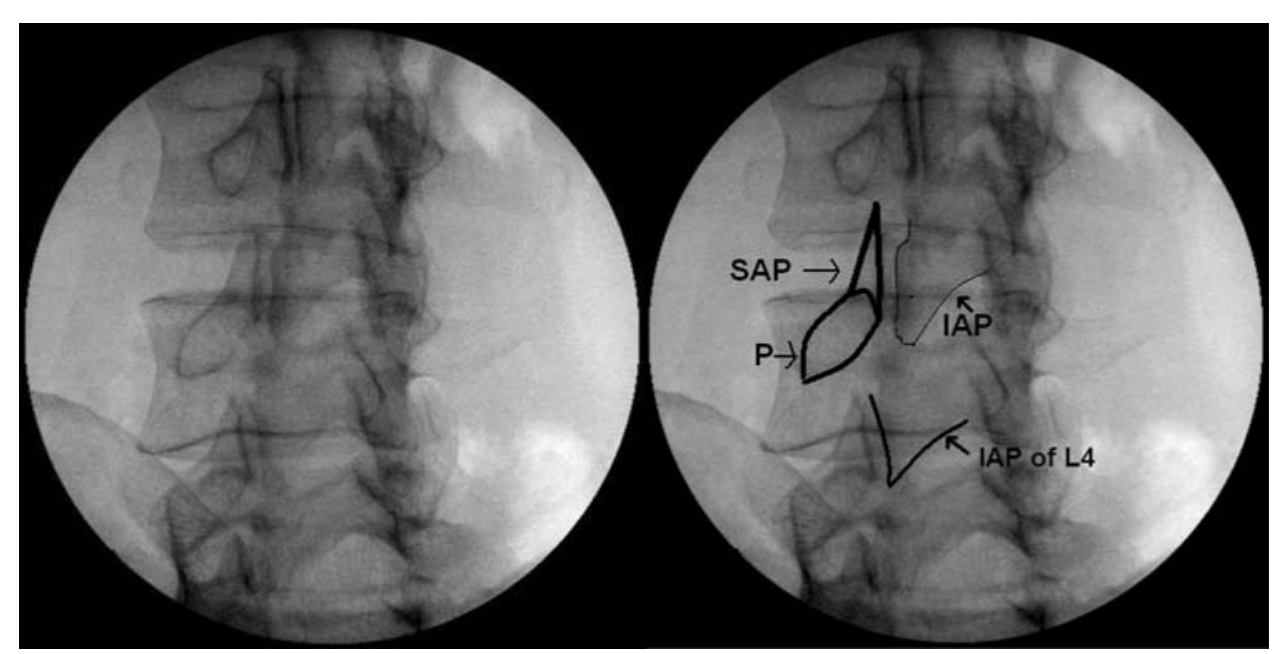


increased range of axial rotation [58-61]. It has been postulated that the increase in axial rotation and subsequent instability place additional stressors upon the facet joint capsules leading to a molecular response, which results in fibrocartilaginous metaplasia in the capsules of facet joints. Boszczyk et al. [62] reported hypertrophic and fibrocartilaginous changes in the facet joint capsules of patients who had undergone lumbar fusion for degenerative instability.

\section{Chemical model}

Changes in load distributions can lead to osteoarthrosis, osteophyte formation, and inflammation [43]. The cartilage and synovium of facet joints are sources of inflammatory cytokines [63]. It has been proposed that painful symptoms may arise not only from mechanical stress discussed previously, but also from the associated inflammatory response involving cytokines such as tumor necrosis factor alpha, interleukin-6, interleukin 1 beta [63, 64], oxygenfree radicals such as nitric oxide $[65,66]$, and inflammatory mediators such as prostaglandins $[63,64,66]$. Interestingly, some have suggested that inflammatory cytokines originating from inflamed synovium may spread to adjacent nerve roots and produce radicular lower extremity symptoms [63, 67-70].

As with other diarthrodial joints, the cartilage of facet joints may also be sex-hormone sensitive [71]. Estrogen has been associated with chondrodestruction [72], although controversy exists as to its actual role in the development of osteoarthritis [73-76]. However, Ha et al. [77] have found a statistically significant association between the increased expression of estrogen receptors on the articular cartilage of facet joints and the severity of facet arthritis.

\section{Diagnosis}

When evaluating a patient with low back pain, the initial differential diagnosis can be broad. While certain symptoms in a patient's history may suggest systemic disease, neoplasm, or acute nerve compression, the history cannot always differentiate the specific etiology of low back pain. Up to $85 \%$ of patients with low back pain do not obtain a specific diagnosis even after work up [78-80]. The diagnosis of facet joint-mediated pain is no exception. The history, physical examination and imaging studies cannot consistently identify facet joint pain [14, 81-86].

A prospective statistical study by Jackson et al. [85], which included 390 patients and examined 127 variables, was not able to identify clinical facet joint syndromes or find predictors of who may respond better to facet joint injections. Furthermore, although pain referral patterns have been identified, investigators have been unable to correlate specific patterns with individual levels [87, 88]. Mooney and Robertson [39] injected hypertonic saline into the facet joints of both symptomatic and asymptomatic patients and noted pain referral patterns that were indistinguishable from pain patterns associated with other etiologies (Fig. 3).

While changes in facet joint architecture can be detected with imaging studies, correlation between radiologic findings and symptoms has also proven unreliable [82]. Although Laslett and colleagues reported clinical guidelines that may be helpful in predicting patient response to facet joint blocks, the study results have not been replicated thus far. At this time, accurately diagnosing facet jointmediated pain by noninvasive techniques remains a challenge [89].

Currently, the principal method of diagnosing facet joint-mediated pain as the cause of low back pain is through the use of controlled local anesthetic blocks of either the medial branches or the facet joint itself. Both of these techniques have been shown to be equally efficacious $[10,82,88,90-92]$. These procedures employ the use of local anesthetics with varying durations of action. For example, a short acting local anesthetic such as lidocaine is injected in either the intra-articular facet joint or upon the medial branches. The patient is observed for pain relief that is consistent with the duration of action of the local anesthetic. Days to weeks after the initial diagnostic block, a second block is then employed with a local anesthetic that has a different duration of action such as bupivacaine.

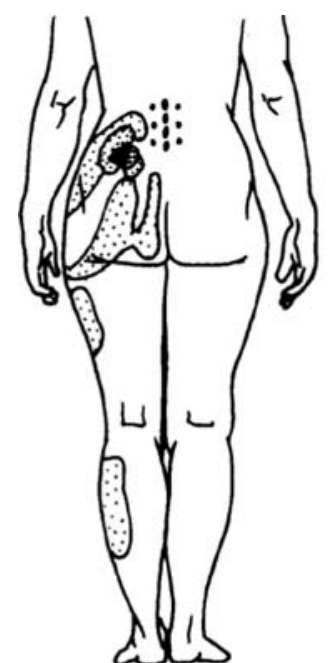

NORMAL

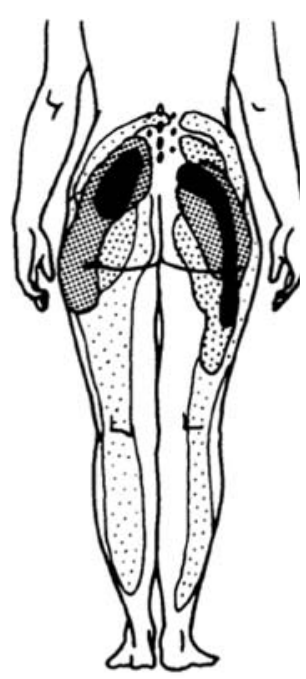

ABNORMAL
Fig. 3 Pain referral patterns for asymptomatic (normal) and symptomatic (abnormal) patients. From Mooney V. Robertson J. The facet syndrome. Clinical Orthopaedics \& Related Research. (115):149-56, 1976 Mar-Apr. Reprinted with permission 
Again, the patient is observed for pain relief that is appropriate to the biological properties of the anesthetic. This second injection is referred to as the confirmatory injection. The value of adding a confirmatory block was demonstrated by Schwarzer et al. [7], who by using the protocol outlined above, noted a false positive rate of $38 \%$ when a single block was used for the diagnosis of facet joint-mediated pain.

Although the value of a confirmatory block is recognized, the definition of a successful block is controversial. In the above study by Schwarzer et al. [7], a 50\% or greater reduction of pain was accepted as a positive block. A $50 \%$ or greater improvement in pain as criteria for a successful diagnostic medial branch block has also been used by other investigators [93-98]. Studies that employed diagnostic intra-articular blocks as apposed to medial branch blocks have also used similar criteria of $50 \%$ or greater improvement of pain [99, 100, 107]. However, others have suggested that a more strict definition of a confirmatory block is necessary to avoid performing radiofrequency denervation on patients who may have low back pain of other etiologies. When more strict criteria are used, the specificity of a diagnostic block may improve.

Other investigators have employed more stringent criteria as the marker for a positive diagnostic medial branch block. For example, in a 10-year clinical audit examining the efficacy of radiofrequency denervation, Gofeld and colleagues [101] accepted a positive response to diagnostic medial branch blocks only if the patient experienced at least a $70 \%$ reduction in pain scores. In a study assessing the efficacy of facet joint anesthesia, Revel et al. [102] considered a positive result only if there was a $75 \%$ or more relief of pain. More recently, Dreyfuss and colleagues [106] excluded patients from subsequent radiofrequency denervation if they did not experience at least $80 \%$ improvement in pain scores. In a randomized double blind trial examining cervical facet joint-mediated pain by Lord et al. [108], patients were required to experience complete $100 \%$ pain relief to be considered as having had a successful diagnostic block.

In a review of the evidence based procedural guidelines that included three randomized controlled trials and two systematic reviews, Hooten et al. [103] proposed the use of $80 \%$ or more relief of pain as the standard for accepting a diagnostic medial branch block as successful. This criteria, however, was challenged by a multi-center retrospective clinical data analysis of 262 patients with chronic low back pain who had undergone lumbar radiofrequency denervation. The study group was divided into two groups of patients. The first group included patients who had experienced greater than or equal to $50 \%$ but less than $80 \%$ pain relief after diagnostic medial branch blocks. The other group represented patients that obtained equal to or greater than $80 \%$ pain relief. There was no significant difference between success rates of subsequent radiofrequency lesioning in these two groups [104].

By utilizing more strict criteria for diagnosing facet joint pain, we limit the number of false positive results. However, as the authors of the above study suggest, the use of more strict criteria may be counterproductive and may lead to the withholding of a potentially therapeutic treatment from patients with treatable facet joint-mediated pain.

As we have illustrated, there is a lack of consensus regarding the definition of a successful diagnostic block. Similarly, there is no universally accepted method of how best to perform these procedures. Although intraarticular facet joint injections are generally considered to be more technically challenging, both medial branch blocks and facet joint injections have their share of technical complications. Furthermore, even the use of local anesthesia with both of these procedures has been called into question. Some physicians will administer a local anesthetic to the muscle and fascia in addition to subcutaneous local anesthesia. This technique is simply an attempt to improve patient comfort by anesthetizing the tissue through which the needle will track. A larger number of false-positive results have been reported with this technique [10, 105]. It is for this reason that some support the use of local anesthetic only superficially or of omitting the use of local anesthetic altogether. It is also important to recognize that in addition to the potential confounders outlined in this review, these methods are only as reliable as the ability of the patient to accurately report their symptoms.

With respect to medial branch blocks, most centers utilize a multiple needle approach whereby separate needles are used for each medial branch that is anesthetized. More recently, however, a new technique involving a single needle has been proposed [109]. Although further studies are needed, initial analysis of this single needle technique suggests similar accuracy to that of the multiple needle approach in ability to anesthetize the medial branch with the advantages of increased efficiency and less patient discomfort [110]. It has also been recognized that when performing medial branch blocks, subtle differences in needle position can have important diagnostic consequences. In a cadaveric study, Dreyfuss et al. [111] reported evidence of local anesthetic spread to other structures such as the intervertebral foramina as well as consistent spread to the posterior muscles of the back. Local anesthetic spread to other potential pain generators may decrease the diagnostic utility of these injections. Of note, in this study, when the needle tip was positioned at a point along the inferior aspect of the transverse process, aberrant flow was minimized. This suggests that when appropriate technique is utilized, spread of anesthetic can be avoided and diagnostic utility may be enhanced. 


\section{Treatment}

Although numerous studies have examined conservative management for low back pain, at the present time, there are no published investigations of conservative management specifically targeted to facet joint pain. However, most experts would agree that the general principles for treatment of nonspecific benign low back pain may be applied. A thorough history and physical exam is always recommended for diagnostic triage. Initial imaging is not necessary unless a specific etiology is strongly suspected or in the presence of "red flag" signs [112]. The use of a multidisciplinary approach is recommended for pain management as it has been associated with improved outcomes [113]. In terms of medications, simple analgesics such as acetaminophen and nonsteroidal anti-inflammatory drugs (NSAIDs) constitute first-line therapy. Acetaminophen has a more favorable side-effect profile since it has not been associated with cardiovascular or gastrointestinal sideeffects. However, with chronic use, hepatic injury is a concern. Studies in patients with osteoarthritis of the knee and hip have previously found that NSAID's provide better analgesia in comparison to acetaminophen [114, 115]. Both benzodiazepine and non-benzodiazepine skeletal muscle relaxants may also provide symptomatic improvement in acute low back pain. However, there is significant controversy regarding the use of controlled substances in the treatment of chronic low back pain [116]. Anticonvulsants such as gabapentin have classically been used for the treatment of neuropathic pain conditions such as diabetic peripheral neuropathy and postherpetic neuralgia [117, 118]. Gabapentin has been evaluated in trials evaluating chronic lumbar radiculopathy [119, 120], and lumbar spinal stenosis [121]. However, these studies were small and had several shortcomings. Studies examining use of gabapentin for facet joint-mediated pain have not been performed. The use of antidepressants, specifically tricyclic antidepressants have shown moderate symptom reduction in patients with chronic low back pain [122, 123]. Again, as with anticonvulsants, trials examining antidepressants specifically for facet joint-mediated pain have not been performed. Although many various adjuvant pain medications have been used to treat radicular and chronic low back pain, there have been no studies to date examining the efficacy of these drugs in patients with documented facetmediated low back pain.

\section{Interventional treatment: radiofrequency denervation}

When suspicion of facet joint-mediated pain is supported by two successful diagnostic blocks, consideration of facet joint denervation may be appropriate. First described by
Shealy in 1975 [124], radiofrequency denervation is a procedure that involves lesioning the medial branches with a combination of electric and magnetic fields. If these nerves become insensate from the process, they cannot relay pain from the facet joints. Radiofrequency ablation of the medial branches is now a commonly used procedure to provide more long-term relief of facet joint-mediated pain.

As with diagnostic medial branch blocks with local anesthetic, the technique and protocol employed for radiofrequency lesioning can have significant impact on the success of the procedure. An example of this was highlighted by Bogduk and colleagues in 1987 [125]. Prompted by reports of poor clinical outcomes with radiofrequency lesioning, they reported on the shape and size of lesions made by the radiofrequency electrodes. It was discovered that lesioning occurred around the distal shaft of the electrode rather than directly at the tip. The consequence of this finding is that suboptimal lesioning occurs if the electrode is oriented directly on the nerve in a perpendicular position. This prompted a revision in the accepted technique to incorporate the placement of the electrode parallel to the targeted medial branch.

Radiofrequency denervation has been shown in some studies to provide significant pain reduction in patients with chronic low back pain for 6 [126] to 12 months [93, 106]. However, other studies have shown little benefit to this procedure. In either case, it is important to consider any design flaws and limitations of these studies. For example, Gallagher et al. [126] examined 41 patients with chronic low back pain who underwent either radiofrequency ablation or a sham treatment. The exact definition of a successful single diagnostic intra-articular injection was not adequately described. Nevertheless, there was a significant difference in outcomes observed between the radiofrequency group and sham group at 1 month. However, this was seen only in the patients who had displayed a good response to the diagnostic blocks. The precise procedure for radiofrequency ablation was also not well described.

Van Kleef et al. [93] described 31 patients who had responded positively ( $\geq 50 \%$ improvement) to a single diagnostic medial branch block and were randomly assigned to either a radiofrequency group or a control group. The control group underwent the identical procedure as the radiofrequency group except for the use of radiofrequency current. One-year follow-up showed statistically significant difference between the treatment and control groups, with higher number of successes (defined as at least 2 point reduction in VAS and $50 \%$ pain reduction) recorded in the treatment group. Unfortunately, there were some important limitations. Only a single diagnostic procedure leading to $50 \%$ or greater pain relief was employed. There was also a small sample size perhaps leading to sampling error. 
A subsequent study by Leclaire et al. [127] involved 70 patients, all of whom had experienced what investigators termed "significant" improvement in low back pain for at least $24 \mathrm{~h}$ after a single diagnostic facet joint injection of both lidocaine $2 \%$ and triamcinolone. The patients were randomized into control and treatment groups, who received identical procedures with the exception that the control group did not experience lesioning with heated probes. There was no significant difference in any of the outcome measures at 12 weeks, which included functional disability according to the Roland-Morris or Oswestry scales, or pain according to the VAS scores. Although this was one of the larger studies examining radiofrequency denervation, it is also important to note that in this study, only one diagnostic block was performed and there was no set definition of what was accepted as a successful diagnostic block. Only "significant pain relief" was described. Furthermore, the description of the radiofrequency technique is incomplete and it is unclear whether the probe was positioned parallel or perpendicular to the medial branch.

A more recent study by van Wijk [107] represents the largest randomized double blind study examining the efficacy of radiofrequency ablation to date. Eighty-one patients were randomized to radiofrequency ablation or a sham procedure after facet joint pain was confirmed with a two level intra-articular facet joint block. There was no difference in the combined primary outcome (VAS, analgesic intake, and physical activity) measure at 3 months. VAS scores improved in both the treatment and control groups but there was no statistically significant difference between groups. In this study, the authors used a 50\% improvement in pain for determining a successful diagnostic facet joint block. However, although the authors recognize that uncontrolled diagnostic blocks may have false-positive effects with a low predictive value, controlled diagnostic blocks were not performed.

Dreyfuss et al. [106] examined the efficacy of lumbar medial branch neurotomy with a thorough and comprehensive protocol, including stringent inclusion and exclusion criteria. Facet joint pain was subsequently confirmed with both diagnostic and confirmatory blocks of the medial branches utilizing an $80 \%$ or greater pain relief criteria for inclusion. Care was taken to ensure that the radiofrequency electrode was positioned parallel to the medial branch. Unique to this study is that 6 weeks after neurotomy, patients underwent an electromyogram to determine the presence or absence of denervation potentials. Eighty-seven percent of patients obtained at least $60 \%$ relief of pain and $60 \%$ of patients obtained at least $90 \%$ relief of pain at 12 months. Although technically sound, this study was limited by its lack of a control group.

Although the study examined cervical facet joint pain rather than lumbar facet joint pain, it is important to consider the study by Lord et al. [108] who presented one of the most rigorous protocols to date. This randomized, double-blind controlled trial included patients who had cervical pain after motor vehicle crashes that had undergone successful diagnostic controlled blocks. In order to proceed to radiofrequency ablation, facet joint pain had to be confirmed with not two but three diagnostic blocks of the medial branches employing $2 \%$ lidocaine, $0.5 \%$ bupivacaine, or saline under strict double blind conditions. The study patient was accepted for radiofrequency lesioning of the medial branches only if they experienced $100 \%$ pain relief with the local anesthetic block and no relief when normal saline had been injected. The median time for return of at least $50 \%$ of preoperative pain level was found to be 263 days in the active-treatment group and 8 days in the control group $(P=0.04)$.

\section{Conclusions}

Despite some of the pitfalls associated with facet joint blocks, they have been shown to be valid, safe, and reliable as a diagnostic tool [128]. Medial branch denervation has shown some promise for the sustained control of lumbar facet joint-mediated pain, but at this time, there is insufficient evidence that it is a wholly efficacious treatment option. This may be simply because we do not have enough highly-powered randomized controlled studies to support its use. Developing a universal algorithm for evaluating facet joint-mediated pain and standard procedural techniques may facilitate the performance of larger outcome studies. Implementing guidelines for the comprehensive reporting of both patient selection and the various aspects of radiofrequency techniques as outlined by Geurts et al. [129] will in turn, allow us to form more powerful evidence-based conclusions.

Open Access This article is distributed under the terms of the Creative Commons Attribution Noncommercial License which permits any noncommercial use, distribution, and reproduction in any medium, provided the original author(s) and source are credited.

\section{References}

1. Cypress BK. Characteristics of physician visits for back symptoms: a national perspective. Am J Public Health. 1991;12: 141-56.

2. U.S. Department of Health and Human Services. Summary Health Statistics for U.S. Adults: National Health Interview Survey, 2002. Vital Health and Statistics Series 10, No. 222.

3. Von Korff M. Studying the natural history of back pain. Spine. 1994;19:2041S-6S.

4. Katz JN. Lumbar disc disorders and low back pain: socioeconomic factors and consequences. J Bone Joint Surg Am. 2006; 88(Suppl 2):21-4. 
5. Goldthwait JE. The lumbosacral articulation: an explanation of many cases of lumbago, sciatica and paraplegia. Boston Med Surg J. 1911;164:365-72.

6. Ghormley RK. Low back pain with special reference to the articular facets, with presentation of an operative procedure. JAMA. 1933;101:773.

7. Schwarzer AC, Aprill CN, Derby R, et al. The false-positive rate of uncontrolled diagnostic blocks of the lumbar zygapophysial joints. Pain. 1994;58:195-200.

8. Manchikanti L, Manchukonda R, Pampati V, Damron KS, McManus CD. Prevalence of facet joint pain in chronic low back pain in post surgical patients by controlled comparative local anesthetic blocks. Arch Phys Med Rehabil. 2007;88(4):449-55.

9. Manchikanti L, Pampati VS, Pakanati RR, et al. Prevalence of patients' facet joint pain in chronic low back pain. Pain Physician. 1999;2:59-64.

10. Bogduk N. International Spinal Injection Society guidelines for performance of spinal injection procedures. Part 1: zygapophysial joint blocks. Clin J Pain. 1997;13:285-302.

11. Schwarzer AC, Derby R, Aprill CN, et al. The value of the provocation response in lumbar zygapophysial joint injections. Clin J Pain. 1994;10:309-13.

12. Manchikanti L, Singh V, Pampati V, et al. Evaluation of the relative contributions of various structures in chronic low back pain. Pain Physician. 2001;4:308-16.

13. Sehgal N, Shah RV, McKenzie-Brown A, Everett CR. Diagnostic utility of facet (zygapophysial) joint injections in chronic spinal pain: a systematic review of evidence. Pain Physician. 2005;8:211-24.

14. Schwarzer AC, Aprill C, Derby R, Fortin JD, Kine G, Bogduk N. Clinical features of patients with pain stemming from the lumbar zygapophysial joints. Is the lumbar facet syndrome a clinical entity? Spine. 1994;19:1132-7.

15. Eubanks JD, Lee MJ, Cassinelli E, Ahn NU. Prevalence of lumbar facet arthrosis and its relationship to age, sex, and race: an anatomic study of cadaveric specimens. Spine. 2007;32(19): 2058-62.

16. Manchikanti L. Interventional pain management: evolving issues for 2003. Pain Physician. 2003;6:125-37.

17. Giles LGF, Taylor JR. Human zygapophyseal joint capsule and synovial fold innervation. Br J Rheumatol. 1987;26:93-8.

18. McLain RF, Pickar JG. Mechanoreceptor endings in human thoracic and lumbar facet joints. Spine. 1998;23:168-73.

19. Giles LGF, Taylor JR. Innervation of lumbar zygpaophysial joint synovial folds. Acta Orthop Scand. 1987;58:43-6.

20. Gronblad M, Weinstein JN, Santavirta S. Immunohistochemical observations on spinal tissue innervation. Acta Orthop Scand. 1991;62:614-22.

21. Bogduk N, Long DM. The anatomy of the so-called "articular nerves" and their relationship to facet denervation in the treatment of low-back pain. J Neurosurg. 1979;51(2):172-7.

22. Bogduk N. The innervation of the lumbar spine. Spine. 1983; 8(3):286-93.

23. Moore KL, Dailey AF. Clinically oriented anatomy. 5th ed. Lippincott: Williams \& Wilkins; 2005.

24. Renfrew DL. Atlas of spine injections. Philadelphia, PA: W.B. Saunders; 2003. p. 79.

25. Masini M, Paiva WS, Araujo AS Jr. Anatomical description of the facet joint innervation and its implication in the treatment of recurrent back pain. J Neurosurg Sci. 2005;49(4):143-6; discussion 146.

26. Lau P, Mercer S, Govind J, Bogduk N. The surgical anatomy of lumbar medial branch neurotomy (facet denervation). Pain Medicine. 2004;5(3):289-98.

27. Adams MA, Hutton WC, Stott JRR. The resistance to flexion of the lumbar intervertebral joint. Spine. 1980;5:245-53.
28. Boden SD, Martin C, Rudolph R, et al. Increase of motion between lumbar vertebrae after excision of the capsule and cartilage of the facets: a cadaver study. J Bone Joint Surg Am. 1994;76:1847-53.

29. Cohen SP, Raja S. Pathogenesis, diagnosis, and treatment of lumbar zygapophysial (facet) joint pain. Anesthesiology. 2007; 106(3):591-614.

30. Horwitz T, Smith RM. An anatomical, pathological and roentgenological study of the intervertebral joints of the lumbar spine and the sacroiliac joints. Am J Roentgenol. 1940;43:173-86.

31. Fujiwara A, Tamai K, An HS, Lim TH, Yoshida H, Kurihashi A, Saotome K. Orientation and osteoarthritis of the lumbar facet joint. Clin Orthop Relat Res. 2001;(385):88-94.

32. Masharawi Y, Rothschild B, Dar G, Peleg S, Robinson D, Been $\mathrm{E}$, et al. Facet orientation in the thoracolumbar spine: threedimensional anatomic and biomechanical analysis. Spine. 2004;29(16): 1755-63.

33. Grogan J, Nowicki BH, Schmidt TA, Haughton VM. Lumbar facet joint tropism does not accelerate degeneration of the facet joints. Am J Neuradiol. 1997;18(7):1325-9.

34. Grobler LJ, Robertson PA, Novtny JE, Pope MH. Etiology of spondylolisthesis: assessment of the role played by lumbar facet joint morphology. Spine. 1993;18:80-91.

35. Boden SD, Riew KD, Yamaguchi K, Branch TP, Schellinger S, Wiesel SW. Orientation of the lumbar facet joints: association with degenerative disc disease. J Bone Joint Surg. 1996;78:403-11.

36. Ianuzzi A, Little JS, Chiu JB, Baitner A, Kawchuk G, Khalsa PS. Human lumbar facet joint capsule strains: I. During physiological motions. Spine J. 2004;4(2):141-52.

37. Pickar JG, McLain RF. Responses of mechanosensitive afferents to manipulation of the lumbar facet in the cat. Spine. 1995;20 (22):2379-85.

38. Hirsch D, Inglemark B, Miller M. The anatomical basis for low back pain. Acta Orthoscan. 1963;33:1-17.

39. Mooney V, Robertson J. The facet syndrome. Clin Orthop Relat Res. 1976;115:149-56.

40. McCall IW. Induced pain referral from posterior lumbar elements in normal subjects. Spine. 1979;4:441-6.

41. Kaplan M, Dreyfuss P, Halbrook B, Bogduk N. The ability of lumbar medial branch blocks to anesthetize the zygapophysial joint. A physiologic challenge. Spine. 1998;23(17):1847-52.

42. Marks R. Distribution of pain provoked from lumbar facet joints and related structures during diagnostic spinal infiltration. Pain. 1989;39:37-40.

43. Brisby H. Pathology and possible mechanisms of nervous system response to disc degeneration. J Bone Joint Surg Am. 2006;88(Suppl 2):68-71.

44. Butler D, Trafimow JH, Anderson JBG, et al. Disc degenerate before facets. Spine. 1990;15:111-3.

45. Fujiwara A, Tamai K, Yamato K, et al. The relationship between facet joint osteoarthritis and disc degeneration of the lumbar spine:an MRI study. Eur Spine J. 1999;8:396-401.

46. Moore RJ, Crotti TN, Osti OL, et al. Osteoarthrosis of the facet joints resulting from anular rim lesions in sheep lumbar discs. Spine. 1999;24:519-25.

47. Lorenz M, Patwardhan A, Vanerby R Jr. Load-bearing characteristics of lumbar facets in normal and surgically altered spinal segments. Spine. 1983;8:122-30.

48. Nachemson A. Lumbar interdiscal pressure. Acta Orthop Scand. 1960;43(suppl):1-104.

49. Yang KH, King AI. Mechanism of facet load transmission as a hypothesis for low back pain. Spine. 1984;9:557.

50. Claude LN, et al. Neuromuscular dysfunction elicited by cyclic lumbar flexion. Muscle Nerve. 2003;27:348-58.

51. Gedalia U, Solomonow M, Zhou BH, Baratta RV, Lu Y, Harris M. Biomechanics of increased exposure to lumbar injury caused 
by cyclic loading. Part 2 . Recovery of reflexive muscular stability with rest. Spine. 1999;24:2461-7.

52. Solomonow M, Baratta RV, Banks A, Freudenberger C, Zhou BH. Flexion-relaxation response to static lumbar flexion in males and females. Clin Biomech. 2003;18:273-9.

53. Solomonow M, Baratta RV, Zhou BH, Burger E, Zieske A, Gedalia A. Muscular dysfunction elicited by creep of lumbar viscoelastic tissue. J Electromyogr Kinesiol. 2003;13:381-96.

54. Solomonow M, He ZB, Baratta RV, Lu Y, Zhu M, Harris M. Biexponential recovery model of lumbar viscoelastic laxity and reflexive muscular activity after prolonged cyclic loading. Clin Biomech. 2000;15:167-75.

55. Solomonow M, Zhou BH, Baratta RV, Lu Y, Harris M. Biomechanics of increased exposure to lumbar injury caused by cyclic loading: Part 1. Loss of reflexive muscular stabilization. Spine. 1999;24:2426-34.

56. Williams M, Solomonow M, Zhou BH, Baratta RV, Harris M. Multifidus spasms elicited by prolonged lumbar flexion. Spine. 2000;25:2916-24.

57. Little JS, Khalsa PS. Human lumbar spine creep during cyclic and static flexion: creep rate, biomechanics, and facet joint capsule strain. Ann Biomed Eng. 2005;33(3):391-401.

58. Fujiwara A, Lim TH, An HS, Tanaka N, Jeon CH, Andersson $\mathrm{GB}$, et al. The effect of disc degeneration and facet joint osteoarthritis on the segmental flexibility of the lumbar spine. Spine. 2000;25(23):3036-44.

59. Kirkaldy-Willis WH, Farfan HF. Instability of the lumbar spine. Clin Orthop. 1982;(165):110-123.

60. Schmidt TA, An HS, Lim TH, et al. The stiffness of lumbar spinal motion segments with a high-intensity zone in the anulus fibrosus. Spine. 1998;23:2167-73.

61. Thompson RE, Pearcy MJ, Downing JWK, et al. Disc lesions and the mechanics of the intervertebral joint complex. Spine. 2000;25:3026-35.

62. Boszczyk BM, Boszczyk AA, Korge A, Grillhosl A, Boos WD, Putz R, et al. Immunohistochemical analysis of the extracellular matrix in the posterior capsule of the zygapophysial joints in patients with degenerative L4-5 motion segment instability. J Neurosurg. 2003;99(1 Suppl):27-33.

63. Igarashi A, Kikuchi S, Konno S, Olmarker K. Inflammatory cytokines released from the facet joint tissue in degenerative lumbar spinal disorders. Spine. 2004;29(19):2091-5.

64. Willburger RE, Wittenberg RH. Prostaglandin release from lumbar disc and facet joint tissue. Spine. 1994;19:2068-70.

65. Brisby H, Ashley H, Diwan AD. In vivo measurement of facet joint nitric oxide in patients with chronic low back pain. Spine. 2007;32(14):1488-92.

66. Amin AR, Dave M, Attur M, et al. COX-2, NO, and cartilage damage and repair. Curr Rheumatol Rep. 2000;2:447-53.

67. Martel-Pelletier J, Alaaeddine N, Pelletier JP. Cytokines and their role in the pathophysiology of osteoarthritis. Front Biosci. 1999;15:694-703.

68. Pelletier JP, Martel-Pelletier J, Abramson SB. Osteoarthritis, an inflammatory disease: potential implication for the selection of new therapeutic targets. Arthritis Rheum. 2001;44:1237-47.

69. Wittenberg RH. In vitro release of prostaglandins and leukotrienes from synovial tissues, cartilage, and bone in degenerative joint diseases. Arthritis Rheum. 1993;36:1444-50.

70. Tachihara H, Kikuchi S, Konno S, Sekiguchi M. Does facet joint inflammation induce radiculopathy?: an investigation using a rat model of lumbar facet joint inflammation. Spine. 2007;32(4): 406-12.

71. Rosner IA, Goldberg VM, Moskowitz RW. Estrogens and osteoarthritis. Clin Orthop. 1986;213:77-83.

72. Tsai CL, Liu TK. Up-regulation of estrogen receptors in rabbit osteoarthritic cartilage. Life Sci. 1992;50:1727-35.
73. Felson DT, Nevitt MC. The effects of estrogen on osteoarthritis. Curr Opin Rheumatol. 1998;10:269-72.

74. Spector TD, Perry LA, Jubb RW. Endogenous sex steroid levels in women with generalized osteoarthritis. Clin Rheumatol. 1991; 10:316-9.

75. Tsai CL, Liu TK, Chen TJ. Estrogen and osteoarthritis: a study of synovial estradiol and estradiol receptor binding in human osteoarthritic knees. Biochem Biophys Res Commun. 1992;183: 1287-91.

76. Tsai CL, Liu TK. Estradiol-induced knee osteoarthrosis in ovariectomized rabbits. Clin Orthop. 1993;291:295-302.

77. Ha KY, Chang CH, Kim YS, Kim KW, Na KH, Lee JS. Expression of estrogen receptor of the facet joints in degenerative spondylolisthesis. Spine. 2005;30(5):562-6.

78. Deyo RA, Rainville J, Kent DL. What can the history and physical examination tell us about low back pain? JAMA. 1992; 268(6):760-5.

79. White AA, Gordon SL. Synopsis: workshop on idiopathic lowback pain. Spine. 1982;7:141-9.

80. Nachemson A. The lumbar spine: an orthopedic challenge. Spine. 1976;1:59-71.

81. Dreyer SJ, Dreyfuss P. Low back pain and the zygapophysial (facet) joints. Arch Phys Med Rehabil. 1996;77:290-300.

82. Dreyfuss P, Dreyer S. Contemporary concepts in spine care: lumbar zygapophysial (facet) joint injections. Spine. 1995;20: 2040-7.

83. Schwarzer AC, Derby R, Aprill CN, Fortin J, Kine G, Bogduk N. Pain from the lumbar zygapophyseal joints: a test of two models. J Spinal Disord. 1994;7:331-6.

84. Schwarzer AC, Wang S, O’Driscoll D, Harrington T, Bogduk N, Laurent R. The ability of computed tomography to identify a painful zygapophysial joint in patients with chronic low back pain. Spine. 1995;20:907-12.

85. Jackson RP, Jacobs RR, Montesano PX. Facet joint injection in low back pain-a prospective statistical study. Spine. 1988;13 (9):966-71.

86. Laslett M, Oberg B, Aprill CN, McDonald B. Zygapophysial joint blocks in chronic low back pain: a test of Revel's model as a screening test. BMC Musculoskelet Disord. 2004;5:43.

87. McCall IW, Park WM, O'Brien JP. Induced pain referral from posterior lumbar elements in normal subjects. Spine. 1979;4(5): $441-6$.

88. Marks RC, Houston T, Thulbourne T. Facet joint injection and facet nerve block: a randomized comparison in 86 patients with chronic low back pain. Pain. 1992;49:325-8.

89. Laslett M, McDonald B, Aprill CN, Tropp H, Oberg B. Clinical predictors of screening lumbar zygapophyseal joint blocks: development of clinical prediction rules. Spine J. 2006;6(4): 370-9.

90. Bogduk N, Aprill C, Derby R. Lumbar zygapophysial joint pain: diagnostic blocks and therapy. In: White A, Schofferman G, editors. Spine care: diagnosis and conservative management. St. Louis: Mosby Publishers; 1995. p. 73-86.

91. Nash TP. Facet joints: intra-articular steroids or nerve block? Pain Clin. 1990;3:77-82.

92. Dreyer SJ, Dreyfuss PH. Low back pain and the zygapophysial (facet) joints. Arch Phys Med Rehabil. 1996;17:290-300.

93. Van Kleef M, Barendse GA, Kessels A, Voets HH, Weber WE, de Lange S. Randomized trial of radiofrequency lumbar facet denervation for chronic low back pain. Spine. 1999;24:1937-42.

94. Lindner R, Sluijter ME, Schleinzer W. Pulsed radiofrequency treatment of the lumbar medial branch for facet pain: a retrospective analysis. Pain Med. 2006;7(5):435-9.

95. Mikeladze G, Espinal R, Finnegan R, Routon J, Martin D. Pulsed radiofrequency application in treatment of chronic zygapophyseal joint pain. Spine J. 2003;3(5):360-2. 
96. Tekin I, Mirzai H, Ok G, Erbuyun K, Vatansever D. A comparison of conventional and pulsed radiofrequency denervation in the treatment of chronic facet joint pain. Clin J Pain. 2007; 23(6):524-9.

97. Birkenmaier C, Veihelmann A, Trouillier HH, Hausdorf J, von Schulze Pellengahr C. Medial branch blocks versus pericapsular blocks in selecting patients for percutaneous cryodenervation of lumbar facet joints. Reg Anesth Pain Med. 2007;32(1):27-33.

98. Bärlocher CB, Krauss JK, Seiler RW. Kryorhizotomy: an alternative technique for lumbar medial branch rhizotomy in lumbar facet syndrome. J Neurosurg. 2003;98(1 Suppl):14-20.

99. Buijs EJ, van Wijk RM, Geurts JW, Weeseman RR, Stolker RJ, Groen GG. Radiofrequency lumbar facet denervation: a comparative study of the reproducibility of lesion size after 2 current radiofrequency techniques. Reg Anesth Pain Med. 2004;29(5): 400-7.

100. Carette S, Marcoux S, Truchon R, et al. A controlled trial of corticosteroid injections into facet joints for chronic low back pain. New Eng1 J Med. 1991;325:1002-7.

101. Gofeld M, Jitendra J, Faclier G. Radiofrequency denervation of the lumbar zygapophysial joints: 10-year prospective clinical audit. Pain Physician. 2007;10(2):291-300.

102. Revel M, Poiraudeau S, Auleley GR, et al. Capacity of the clinical picture to characterize low back pain relieved by facet joint anesthesia: proposed criteria to identify patients with painful facet joints. Spine. 1998;23:1972-7.

103. Hooten WM, Martin DP, Huntoon MA. Radiofrequency neurotomy for low back pain: evidence-based procedural guidelines. Pain Med. 2005;6(2):129-38. Review.

104. Cohen SP, Stojanovic MP, Crooks M, Kim P, Schmidt CR, Shields LC, Croll LS, Hurley RW. Lumbar zygapophysial (facet) joint radiofrequency denervation success as a function of pain relief during diagnostic medial branch blocks: a multicenter analysis. Spine J. 2007; Jun 18. (Epub ahead of print).

105. Ackerman WE, Munir MA, Zhang JM, Ghaleb A. Are diagnostic lumbar facet injections influenced by pain of muscular origin? Pain Pract. 2004;4:286-91.

106. Dreyfuss P, Halbrook B, Pauza K, Joshi A, McLarty J, Bogduk N. Efficacy and validity of radiofrequency neurotomy for chronic lumbar zygapophysial joint pain. Spine. 2000;25:1270-7.

107. van Wijk RM, Geurts JW, Wynne HJ, Hammink E, Buskens E, Lousberg R, et al. Radiofrequency denervation of lumbar facet joints in the treatment of chronic low back pain: a randomized, double-blind, sham lesion-controlled trial. Clin J Pain. 2005; 21(4):335-44.

108. Lord SM, Barnsley L, Wallis BJ, McDonald GJ, Bogduk N. Percutaneous radio-frequency neurotomy for chronic cervical zygapophyseal-joint pain. N Engl J Med. 1996;335(23):1721-6.

109. Stojanovic MP, Zhou Y, Hord D, Vallejo R, Cohen SP. The single needle approach for multiple medial branch blocks: a new technique. Clin J Pain. 2003;9:134-7.

110. Stojanovic MP, Dey D, Hord ED, Zhou Y, Cohen SP. A prospective crossover comparison study of the single-needle and multiple-needle techniques for facet-joint medial branch block. Reg Anesth Pain Med. 2005;30(5):484-90.

111. Dreyfuss P, Schwarzer AC, Lau P, Bogduk N. Specificity of lumbar medial branch and L5 dorsal ramus blocks: a computed tomography study. Spine. 1997;22:895-902.

112. Airaksinen O, Brox JI, Cedraschi C, et al. European guidelines for the management of chronic nonspecific low back pain. Eur Spine J. 2006;15(Suppl 2):S192-300.
113. Nachemson AL, Jonsson E, editors. Neck and back pain: the scientific evidence of causes, diagnosis and treatment. Lippincott: Williams and Wilkins; 2000.

114. Towheed TE, Maxwell L, Judd MG, Catton M, Hochberg MC, Wells G. Acetaminophen for osteoarthritis. Cochrane Database Syst Rev. 2006;25(1):CD004257. Review.

115. Wegman A, van der Windt D, van Tulder M, Stalman W, de Vries T. Nonsteroidal antiinflammatory drugs or acetaminophen for osteoarthritis of the hip or knee. A systematic review of evidence and guidelines. J Rheumatol. 2004;31(2):344-54.

116. Van Tulder MW, Touray T, Furlan AD, Solway S, Bouter LM, Cochrane Back Review Group. Muscle relaxants for nonspecific low back pain: a systematic review within the framework of the cochrane collaboration. Spine. 2003;28(17):1978-92.

117. Backonja M, Beydoun A, Edwards K, et al. Gabapentin for the symptomatic treatment of painful neuropathy in patients with diabetes mellitus: a randomized controlled trial. JAMA. 1998; 280(21):1831-6.

118. Rowbotham M, Harden N, Stacey B, Bernstein P, MagnusMiller L. Gabapentin for the treatment of postherpetic neuralgia: a randomized controlled trial. JAMA. 1998;280(21):1837-42.

119. McCleane GJ. Does gabapentin have an analgesic effect on background, movement and referred pain? A randomized, double-blind, placebo controlled study. Pain Clin. 2001;13:103.

120. Yildirim K, Sisecioglu M, Karatay S, et al. The effectiveness of gabapentin in patients with chronic radiculopathy. Pain Clin. 2003; 15:213.

121. Yaksi A, Ozgonenel L, Ozgonenel B. The efficiency of gabapentin therapy in patients with lumbar spinal stenosis. Spine. 2007;32:939.

122. Schnitzer TJ, Ferraro A, Hunsche E, Kong SX. A comprehensive review of clinical trials on the efficacy and safety of drugs for the treatment of low back pain. J Pain Symptom Manage. 2004;28(1):72-95.

123. Staiger TO, Gaster B, Sullivan MD, Deyo RA. Systematic review of antidepressants in the treatment of chronic low back pain. Spine. 2003;28(22):2540-5.

124. Shealy CN. Percutaneous radiofrequency denervation of spinal facets. Treatment for chronic back pain and sciatica. J Neurosurg. 1975;43(4):448-51.

125. Bogduk N, Macintosh J, Marsland A. Technical limitations to the efficacy of radiofrequency neurotomy for spinal pain. Neurosurgery. 1987;20(4):529-35.

126. Gallagher J, Petriccione diVadi PL, Wedley JR, Hamann W, Ryan P, Chikanza I, et al. Radiofrequency facet joint denervation in the treatment of low back pain: a prospective controlled double-blind study to assess its efficacy. Pain Clin. 1994;7:193-9.

127. Leclaire R, Fortin L, Lambert R, Bergeron YM, Rossignol M. Radiofrequency facet joint denervation in the treatment of low back pain: a placebo-controlled clinical trail to assess its efficacy. Spine. 2001;26:1411-7.

128. Sehgal N, Dunbar EE, Shah RV, Colson J. Systematic review of diagnostic utility of facet (zygapophysial) joint injections in chronic spinal pain: an update. Pain Physician. 2007;10(1):213-28.

129. Geurts JW, van Wijk RM, Stolker RJ, Groen GJ. Efficacy of radiofrequency procedures for the treatment of spinal pain: a systematic review of randomized clinical trials. Reg Anesth Pain Med. 2001;26(5):394-400. 